\title{
Both Rural and Urban SNAP Recipie
by Proposed Work Requirements
}

\author{
Jessica A. Carson
}

$\mathrm{W}$ ith the expiration of the current Farm Bill on September 30, 2018, the House and Senate are working in conference committee to reconcile their versions of its replacement. A major difference between the two is the House's inclusion of a more intensive work requirement. By narrowing the parental work exemption to only those with children under age 6 , and requiring recipients up to age 60 (rather than 50) to work, the proposed House bill would newly subject about 16 percent of SNAP recipients in rural and urban places alike to work requirements. More than half (53 percent) of Americans who would be newly subjected to work requirements are already working 20 hours or more per week. Among those who are not working, 28.4 percent report "taking care of home/family" as the reason for not working, with 60 percent of this group having two or more children in the household. Given the scarcity and expense of child care nationwide, meeting work requirements may be challenging for some.

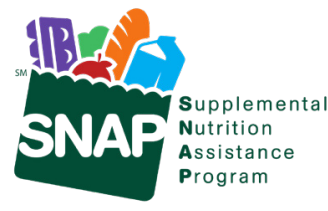

The Food and Nutrition Service reports that the average monthly SNAP benefit in 2016 was $\$ 255$ per household.

See related publications at carsey.unh.edu

- SNAP Declines Continue in 2016, but Not for Rural Places (November 2017)

- Three in Ten Rural and Urban Medicaid Recipients Affected by Potential Work Requirements (July 2017)

\section{SNAP RECIPIENTS AFFECTED BY PROPOSED WORK REQUIREMENTS BY PLACE TYPE, 2014-2016, INCLUDING WORK STATUS OF THOSE NEWLY SUBJECTED TO WORK REQUIREMENTS}

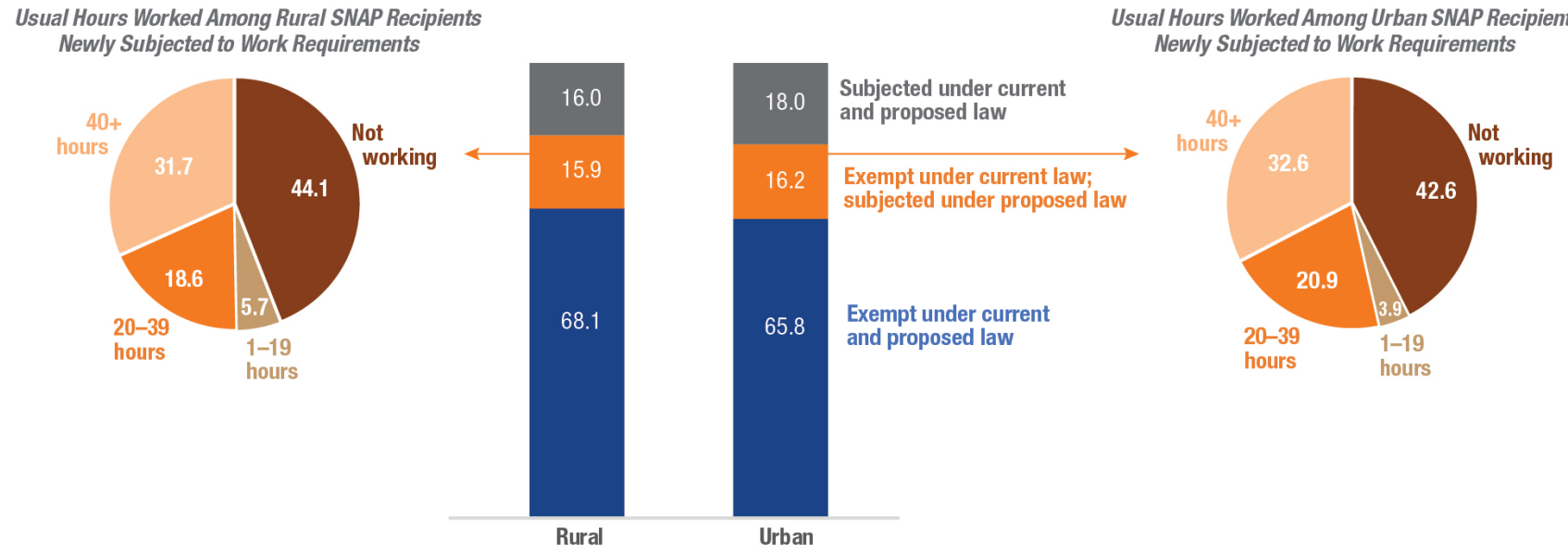

Source: Current Population Survey, Annual Social and Economic Supplement, 2015-2017. Note: Differences between rural and urban places are statistically significant for the share who are exempt under both current and proposed law, and for the share who are subjected under both, but not for those who are newly subjected ( $p<0.05)$. Along with the exemption for parents of young children, SNAP work requirements would also exclude recipients who care for an incapacitated household member, or who are disabled themselves. Identifying SNAP recipients who care for such household members and those who adhere precisely to the FNS definition of "disabled" in the CPS is somewhat difficult, so more SNAP recipients may actually be exempt for those reasons than represented here. 